\title{
Clinical Reasoning: A 28-Year-Old Woman With Vision Loss and an Unusual Gait
}

Jenny C. Dohlman, MD, Bart K. Chwalisz, MD, and Christopher D. Stephen, MB ChB, MRCP (UK), MS

Neurology ${ }^{\circledR} 2021 ; 97:$ e1860-e1865. doi:10.1212/WNL.0000000000012446

Figure Fundoscopy, MRI, OCT, and Goldmann Visual Field Test Results

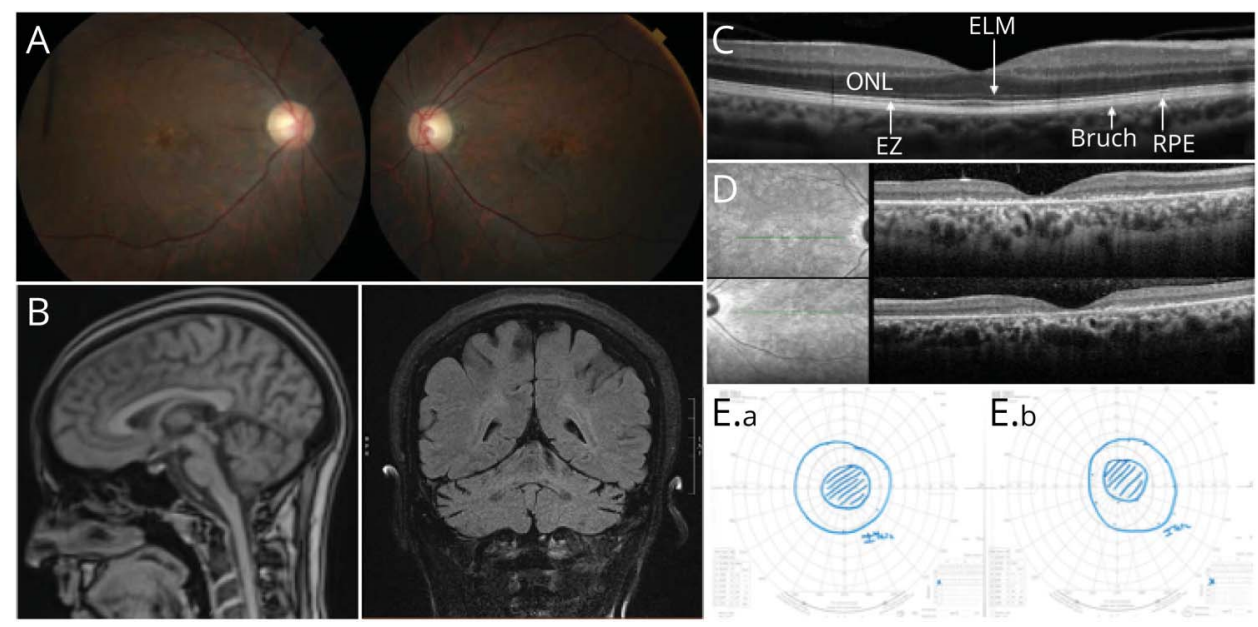

(A) Fundoscopic photographs: Bilateral temporal optic disc pallor, vessel attenuation, and macular pigmentary and atrophic changes were noted on fundoscopic examination. (B) Brain MRI (T1-weighted): Mild global cerebral and cerebellar atrophy were noted on imaging. (C) A normal optical coherence tomography (OCT) scan demonstrates outer retinal structures including the outer nuclear layer (ONL), external limiting membrane (ELM), ellipsoid zone (EZ), retinal pigment epithelium (RPE), and Bruch membrane. (D) OCT of this patient demonstrated diffuse retinal thinning and outer retinal atrophy in both eyes. (E) Goldmann visual field testing: Field constriction and a centrocecal scotoma were noted in the left eye (E.a) and right eye (E.b).

\section{Section 1}

A 28-year-old woman with a history of migraine with visual aura and normal growth and development presented with gradually progressive vision loss since the age of 13 years (legally blind since the age of 20 years) and with later development of gait imbalance and falls beginning at the age of 25 . Ancestry was Dominican on both sides, and the family history was significant for a father with an onset of tremor, dysarthria, and balance difficulties at the age of 47 and a paternal half-sister with an onset of tremor at the age of 6, both without visual loss. Her 3 brothers and 2 children were healthy.

Ophthalmologic examination at the age of 28 and later at the age of 29 revealed visual acuity of light perception in both eyes. Pupils were equal, round, and sluggishly reactive to light with no afferent pupillary defect. On oculomotor examination, eyes were quiet at rest, there were trace abduction deficits in both eyes, and subtle saccadic pursuits, without nystagmus. However, the predominant feature was of unequivocally slow horizontal greater than vertical saccades, without saccadic hypermetria or hypometria. Intraocular pressures/anterior segment

\author{
Correspondence \\ Dr. Dohlman \\ jenny_dohlman2@ \\ meei.harvard.edu
}

\footnotetext{
Department of Ophthalmology (J.C.D., B.K.C.), Massachusetts Eye and Ear Infirmary, Harvard Medical School, Boston, MA; and Department of Neurology (B.K.C., C.D.S.), Massachusetts General Hospital, Boston, MA.

Go to Neurology.org/N for full disclosures. Funding information and disclosures deemed relevant by the authors, if any, are provided at the end of the article.

B.K. Chwalisz and the last author C.D. Stephen contributed equally to this work and should be cosenior authors.
} 
examination were unremarkable. Fundoscopic examination revealed bilateral temporal optic disc pallor, vessel attenuation, macular pigmentary changes, and atrophy (figure).

Further examination at the age of 29 (Video 1) revealed features of the cerebellar motor syndrome, with slow, mildly dysarthric speech, lower greater than upper extremity appendicular dysmetria, a positive Romberg sign, and a spastic and ataxic gait. Other pertinent features included lower greater than upper extremity spasticity, pathologically brisk tendon reflexes, and bilateral ankle clonus, with preserved strength and sensation.

\section{Questions for Consideration:}

1. Where do the patient's neurologic examination findings localize?

2. What diagnostic testing should be done to further characterize the patient's vision loss?

GO TO SECTION 2 


\section{Section 2}

The patient's dysarthria, ataxia, hyperreflexia, and spasticity suggest cerebellar and upper motor neuron dysfunction. Brain magnetic resonance imaging revealed mild global cerebral and cerebellar atrophy (figure). The correlation between the patient's cerebellar signs and vision loss were at this point unclear. To further investigate an etiology for the vision loss, several diagnostic tests were performed.

In a normal patient, optical coherence tomography (OCT) demonstrates intact and distinct retinal layers as depicted in figure, whereas the OCT of this patient demonstrated diffuse retinal thinning and outer retinal atrophy in both eyes (figure). Goldmann visual field testing revealed field constriction and a centrocecal scotoma in each eye (figure). Full field electroretinography (ERG) demonstrated reduced and delayed full field cone signals and a lesser decrease in rod signals in both eyes. This was compatible with a cone-rod dystrophy: an inherited, progressive deterioration of cone and rod cells that characteristically causes vision loss and demonstrates depression of cone and rod photoreceptor function on ERG. ${ }^{1}$

\section{Questions for Consideration:}

1. What is the differential diagnosis for retinal disease in the setting of cerebellar ataxia?

GO TO SECTION 3 


\section{Section 3}

There is a wide differential diagnosis for ophthalmologic features in ataxia, whereas the differential diagnosis for retinal disease in movement disorders is narrower and includes mitochondrial disease, nutritional deficiencies, inborn errors of metabolism, and inherited retinal dystrophies in genetic ataxia:

\section{Mitochondrial Diseases}

Kearns-Sayre syndrome is a mitochondrial myopathy characterized by chronic progressive external ophthalmoplegia, cardiac conduction defects, and a pigmentary retinopathy. Cerebellar ataxia may be a feature. ${ }^{2}$ The retinopathy tends to have a diffuse, stippled "salt and pepper" appearance, but in contrast to our patient, vision is generally good at the time of diagnosis, with normal or only mildly abnormal ERG. ${ }^{3}$ Neuropathy, ataxia, and retinitis pigmentosa can present with ataxia, pigmentary retinopathy, muscle weakness, developmental delay, sensory polyneuropathy, epilepsy, and dementia. ${ }^{4}$ The characteristic retinopathy has a bone spicule appearance as in retinitis pigmentosa, but bull's eye maculopathy and salt and pepper retinopathy have also been reported. ${ }^{5}$ Mitochondrial disorders typically follow maternal inheritance or occur spontaneously.

\section{Inborn Errors of Metabolism}

Aceruloplasminemia, a rare autosomal recessive disorder in which ceruloplasmin is not synthesized properly and leads to copper deficiency, has clinical manifestations including ataxia, cognitive dysfunction, and retinal degeneration (although with preserved visual acuity). ${ }^{6,7}$ Pantothenate kinase-associated neurodegeneration is an autosomal recessive disorder characterized by brain iron accumulation (with an "eye of the tiger" sign on imaging), leading to movement disorders and a pigmentary retinopathy. ${ }^{7}$ Refsum disease is a disorder of peroxisomal function that results in retinitis pigmentosa, cerebellar ataxia, and polyneuropathy. Of note, unlike other peroxisomal disorders, this is a treatable disorder that is responsive to restriction of phytanic acid intake. ${ }^{8}$

\section{Nutritional Deficiencies}

These are potentially treatable causes of ataxia with visual loss. In ataxia with vitamin $\mathrm{E}$ deficiency, there is childhood onset of ataxia and progressive weakness (sometimes mimicking Friedreich ataxia) but is associated with visual loss and pigmentary retinopathy, and a characteristic head titubation. ${ }^{9}$ Other nutritional causes of vision loss and ataxia such as vitamin B12 deficiency exist, but loss of vision is secondary to optic neuropathy rather than the retinal pathology seen in this patient's condition. ${ }^{10}$

\section{Inherited Retinal Dystrophy in Genetic Ataxia}

Spinocerebellar ataxia (SCA) and other genetic ataxias may also present with retinal disease. ${ }^{11}$ Retinal degeneration is seen in SCA7 and in rare cases of SCA1, 2, and $3,{ }^{12-14}$ whereas optic atrophy can be seen in SCA1, 7, 9, and 28. ${ }^{15-17}$ Other, less common neurogenetic ataxias manifesting with retinal degeneration include infantile cerebellar-retinal degeneration but, in contrast to our patient, tends to be present from birth. ${ }^{7}$ Optic atrophy is also a core feature of the cerebellar ataxia, areflexia, pes cavus, optic atrophy, and sensorineural hearing loss syndrome, which is caused by ATP1A3 mutations and can overlap with other ATP1A3-related disorders. ${ }^{18}$

Our patient demonstrated decreased cone and rod photoreceptor function on ERG, consistent with a cone-rod dystrophy. The only cone-rod dystrophy on our differential associated with cerebellar signs, autosomal dominant inheritance, and an adultonset was SCA7. ${ }^{1}$ Based on these findings, a comprehensive ataxia repeat expansion panel was performed, which detected an allele with 49 cystosine, adenine, guanine (CAG) repeats in the ATXN7 gene (normal 7-27, mutable allele 28-33, and pathogenic $\geq 34)^{19}$ and 10 repeats in the normal allele. This was diagnostic for SCA7 in the full penetrance range. She was also incidentally found to have an intermediate allele in the ATXN2 gene, with 32 repeats (normal $\leq 31$, intermediate $32-34$, reduced penetrance $33-34$, and fully penetrant $\geq 35$ ). ${ }^{20}$

\section{Discussion}

The SCAs are a group of autosomal dominant neurogenetic movement disorders primarily involving the cerebellum and its associated pathways, resulting in slowly progressive diffculty with gait, balance, speech and swallowing, limb incoordination, and abnormal eye movements. ${ }^{15}$ There are currently 48 identified SCAs, ${ }^{21}$ with an overall prevalence of $1-5$ per 100,000 people. ${ }^{17}$ Common causes include triplet repeat ataxias, most commonly involving CAG repeat expansions, which translate into toxic polyglutamine proteins, leading to neuronal dysfunction. ${ }^{22}$ Important aspects to consider when attempting to refine a diagnosis of possible SCA (in addition to an ideally autosomal dominant-appearing family history) include the following: ${ }^{19}$

1. Age at onset (early onset vs late onset [SCA6 most common])

2. Rate of disease progression (SCA1 fastest, followed by SCA2 and SCA3; SCA6 slowest)

3. Ancestry (origins from the Portuguese Azore Islands may suggest SCA3/Machado-Joseph disease, whereas Cuban ancestry may suggest SCA2, etc.)

4. Specific clinical features, including the presence of a pure cerebellar ataxia vs additional nonataxia clinical featuresincluding oculomotor manifestations, ${ }^{23}$ other movement disorders (chorea [SCA17], parkinsonism, dystonia [earlyonset SCA3], myoclonus etc.), cognitive impairment/frank dementia (SCA48 archetypal example), ${ }^{21}$ spasticity, prominent peripheral neuropathy, significant visual (SCA7), or sensorineural hearing loss (SCA36), ${ }^{24}$ which may be pathognomonic

5. Imaging features, including the degree of cerebellar atrophy (for example, prominent pontocerebellar atrophy in SCA2 $)^{25}$

Ophthalmologic manifestations vary based on the SCA subtype and can include slow saccades, ophthalmoparesis, eyelid 
retraction, nystagmus, retinal degeneration, ptosis, and optic atrophy, among others. ${ }^{17,23}$ Ophthalmologic findings in SCA type 7 may include loss of central vision, tritan color defects, macular changes on fundus examination, paracentral scotomas on visual field testing, and abnormalities of cone function, followed by rod function on ERG. ${ }^{26}$ Our patient's findings were consistent with this; however, vision was too poor to adequately test color vision. Although patients with SCA7 may have a number of oculomotor features, slowing of pursuits and saccades may be the only initial feature and may eclipse other cerebellar oculomotor abnormalities as the slowing progresses, in some cases, leading to complete ophthalmoplegia. ${ }^{23}$ Thus, the combination of pathologically slow saccades and the early visual loss clinch the diagnosis and differentiates this from SCA2, where there is a similar age at onset and early slowing of saccadic eye movements, but visual loss does not generally occur, although rare exceptions exist. ${ }^{14}$ There are also rare cases of cone-rod dystrophy reported in SCA1, ${ }^{12}$ although saccadic slowing generally occurs in advanced disease. $^{23}$ This highlights the importance of the ophthalmologist in the diagnosis of SCA7 because ophthalmologic features may predate the development of clinical ataxia.

SCA7 is diagnosed by the identification of a pathogenic CAG trinucleotide repeat expansion in the ATXN7 gene. Genetic testing for SCA7 and other trinucleotide repeat disorders requires dedicated testing for repeat expansions (typically as part of an SCA panel) because these disorders may be missed in standard genetic testing and whole exome/genome testing. ${ }^{25}$ SCA7 has a phenotypic spectrum ranging from a severe infantile/early childhood-onset form (failure to thrive, loss of motor milestones, and early death) to an adult-onset form marked by progressive ataxia, early progressive oculomotor slowing, and vision loss secondary to cone-rod dystrophy, with spasticity and pyramidal signs, as seen in our patient. ${ }^{26}$ In addition to ataxia, other movement disorders associated with SCA7 include dystonia and parkinsonism. ${ }^{26}$ Genetic anticipation can be striking in SCA7 to the point that a child may be diagnosed with what is thought to be an unrelated neurodegenerative disease before a parent or grandparent with SCA7 becoming symptomatic. ${ }^{19}$ Infantile cases tend to occur in paternal disease transmission, with extreme anticipation and large increases in repeat expansion when compared with maternal transmission. ${ }^{27}$ Such paternally inherited anticipation was present in this case because our patient became symptomatic substantially earlier than her father did: her symptoms began at the age of 13 years, whereas his began at the age of 47 years and were much milder.

The significance of the additional intermediate allele in the ATXN2 gene in our patient's case is uncertain, but we postulate that this may reflect her ethnic background because the Dominican Republic (which has no data regarding SCA2 allelic frequency) is a neighboring island to Cuba, where high normal and intermediate alleles are common in the general population. ${ }^{20}$ Such intermediate alleles have been shown to cause late-onset SCA2, and although it is not possible to rule out some influence of this allele (through genetic interaction), her phenotype was fully consistent with classical SCA $7 .^{20,28}$

The management of SCA7 and other cerebellar disorders is multidisciplinary and treatment currently symptomatic. ${ }^{25}$ Our patient received baclofen (for spasticity), riluzole, and antioxidants. ${ }^{25}$ There has been recent interest in the development of an antisense oligonucleotide as a potential treatment based on the results of a study demonstrating reduced ATXN7 expression and improved visual function in a mouse model. ${ }^{29}$ This technology has already been used to effectively treat ophthalmic conditions (e.g., cytomegalovirus retinitis) and neurologic conditions (including spinal muscular atrophy), and thus holds great promise for the treatment of the SCAs. ${ }^{6}$ Prognosis in the common triplet repeat SCAs is highly variable, with young-onset cases tending to have longer repeat expansions and more rapid progression, and shorter and even intermediate expansions sometimes resulting in a late-onset, slowly progressive course. ${ }^{19}$ In SCA7, there is relentless progression of visual loss and ataxia, leading to blindness, dysarthria, and dysphagia, with a shortened lifespan. ${ }^{30}$

\section{Acknowledgment}

The authors would like to acknowledge Ryan Jaslow and Keith DeVincent for their assistance with video editing.

\section{Study Funding}

The authors report no targeted funding.

\section{Disclosure}

J.C. Dohlman reports no disclosures relevant to the manuscript; C.D. Stephen reports no disclosures relevant to the manuscript; B.K. Chwalisz reports no disclosures relevant to the manuscript. Go to Neurology.org/ $\mathrm{N}$ for full disclosures.

Appendix Authors

\begin{tabular}{|c|c|c|}
\hline Author & Location & Contribution \\
\hline $\begin{array}{l}\text { Jenny C } \\
\text { Dohlman, MD }\end{array}$ & $\begin{array}{l}\text { Massachusetts Eye and } \\
\text { Ear Infirmary/Harvard } \\
\text { Medical School, Boston, } \\
\text { MA }\end{array}$ & $\begin{array}{l}\text { Drafting/revision of the } \\
\text { manuscript for content, } \\
\text { including medical writing } \\
\text { for content, study concept } \\
\text { or design, and analysis or } \\
\text { interpretation of data }\end{array}$ \\
\hline $\begin{array}{l}\text { Bart K Chwalisz, } \\
\text { MD }\end{array}$ & $\begin{array}{l}\text { Massachusetts Eye and } \\
\text { Ear Infirmary/Harvard } \\
\text { Medical School, Boston, } \\
\text { MA }\end{array}$ & $\begin{array}{l}\text { Drafting/revision of the } \\
\text { manuscript for content, } \\
\text { including medical writing } \\
\text { for content, major role in } \\
\text { the acquisition of data, } \\
\text { study concept or design, } \\
\text { and analysis or } \\
\text { interpretation of data }\end{array}$ \\
\hline $\begin{array}{l}\text { Christopher D } \\
\text { Stephen, MB } \\
\text { ChB, MRCP (UK), } \\
\text { MS }\end{array}$ & $\begin{array}{l}\text { Massachusetts General } \\
\text { Hospital/Harvard Medical } \\
\text { School, Boston, MA }\end{array}$ & $\begin{array}{l}\text { Drafting/revision of the } \\
\text { manuscript for content, } \\
\text { including medical writing } \\
\text { for content, major role in } \\
\text { the acquisition of data, } \\
\text { and analysis or } \\
\text { interpretation of data }\end{array}$ \\
\hline
\end{tabular}




\section{References}

1. Gill JS, Georgiou M, Kalitzeos A, Moore AT, Michaelides M. Progressive cone and cone-rod dystrophies: clinical features, molecular genetics and prospects for therapy. Br J Ophthalmol. 2019;103(5):711-20.

2. Yamashita S, Nishino I, Nonaka I, Goto YI. Genotype and phenotype analyses in 136 patients with single large-scale mitochondrial DNA deletions. J Hum Genet. 2008;53(7):598.

3. Mullie MA, Harding AE, Petty RK, Ikeda H, Morgan-Hughes JA, Sanders MD. The retinal manifestations of mitochondrial myopathy. A study of 22 cases. Arch Ophthalmol. 1985;103(12):1825-1830.

4. Holt IJ, Harding AE, Petty RK, Morgan-Hughes JA. A new mitochondrial disease associated with mitochondrial DNA heteroplasmy. Am J Hum Genet. 1990;46(3):428-433.

5. Ortiz RG, Newman NJ, Shoffner JM, Kaufman AE, Koontz DA, Wallace DC. Variable retinal and neurologic manifestations in patients harboring the mitochondrial DNA 8993 mutation. Arch Ophthalmol. 1993;111(11):1525-1530.

6. Miyajima H, Hosoi Y. Aceruloplasminemia. In: Adam MP, Ardinger HH, Pagon RA, et al., eds. GeneReviews ${ }^{\circledast}$. University of Washington; 1993. ncbi.nlm.nih.gov/books/ NBK1493/ (Accessed January 30, 2021).

7. Silver G, Mercimek-Andrews S. Inherited metabolic disorders presenting with ataxia. Int J Mol Sci. 2020;21(15):5519.

8. Baldwin EJ, Gibberd FB, Harley C, Sidey MC, Feher MD, Wierzbicki AS. The effectiveness of long-term dietary therapy in the treatment of adult Refsum disease. J Neurol Neurosurg Psychiatry. 2010;81(9):954-957.

9. Hentati F, El-Euch G, Bouhlal Y, Amouri R. Ataxia with vitamin E deficiency and abetalipoproteinemia. Handb Clin Neurol. 2012;103:295-305.

10. Green R, Datta Mitra A. Megaloblastic anemias: nutritional and other causes. Med Clin North Am. 2017;101(2):297-317.

11. Park JY, Joo K, Woo SJ. Ophthalmic manifestations and genetics of the polyglutamine autosomal dominant spinocerebellar ataxias: a review. Front Neurosci. 2020;14:892.

12. Thurtell MJ, Biousse V, Newman NJ. Rod-cone dystrophy in spinocerebellar ataxia type 1. Arch Ophthalmol. 2011;129(7):956-958.

13. Isashiki Y, Kii Y, Ohba N, Nakagawa M. Retinopathy associated with MachadoJoseph disease (spinocerebellar ataxia 3) with CAG trinucleotide repeat expansion. Am J Ophthalmol. 2001;131(6):808-810.

14. Babovic-Vuksanovic D, Snow K, Patterson MC, Michels VV. Spinocerebellar ataxia type 2 (SCA 2) in an infant with extreme CAG repeat expansion. Am J Med Genet. 1998;79(5):383-387.

15. Schöls L, Bauer P, Schmidt T, Schulte T, Riess O. Autosomal dominant cerebellar ataxias: clinical features, genetics, and pathogenesis. Lancet Neurol. 2004;3(5):291-304.
16. Abe T, Abe K, Aoki M, Itoyama Y, Tamai M. Ocular changes in patients with spinocerebellar degeneration and repeated trinucleotide expansion of spinocerebellar ataxia type 1 gene. Arch Ophthalmol. 1997;115(2):231-236.

17. Sun YM, Lu C, Wu ZY. Spinocerebellar ataxia: relationship between phenotype and genotype - a review. Clin Genet. 2016;90(4):305-314.

18. Sweney MT, Newcomb TM, Swoboda KJ. The expanding spectrum of neurological phenotypes in children with ATP1A3 mutations, Alternating Hemiplegia of Childhood, Rapid-onset Dystonia-Parkinsonism, CAPOS and beyond. Pediatr Neurol. 2015;52(1):56-64.

19. Klockgether T, Mariotti C, Paulson HL. Spinocerebellar ataxia. Nat Rev Dis Primers. 2019;5(1):24

20. Laffita-Mesa JM, Velázquez-Pérez LC, Santos Falcón N, et al. Unexpanded and intermediate CAG polymorphisms at the SCA2 locus (ATXN2) in the Cuban population: evidence about the origin of expanded SCA2 alleles. Eur J Hum Genet. 2012;20(1):41-49.

21. De Michele G, Galatolo D, Barghigiani M, et al. Spinocerebellar ataxia type 48: last but not least. Neurol Sci. 2020;41(9):2423-2432.

22. Paulson HL, Shakkottai VG, Clark HB, Orr HT. Polyglutamine spinocerebellar ataxias - from genes to potential treatments. Nat Rev Neurosci. 2017;18(10):613-626.

23. Stephen CD, Schmahmann JD. Eye movement abnormalities are ubiquitous in the spinocerebellar ataxias. Cerebellum. 2019;18(6):1130-1136.

24. García-Murias M, Quintáns B, Arias M, et al. "Costa da Morte" ataxia is spinocerebellar ataxia 36: clinical and genetic characterization. Brain. 2012;135(Pt 5): 1423-1435.

25. Stephen CD, Brizzi KT, Bouffard MA, et al. The comprehensive management of cerebellar ataxia in adults. Curr Treat Options Neurol. 2019;21(3):9.

26. La Spada AR. Spinocerebellar ataxia type 7. In: Adam MP, Ardinger HH, Pagon RA, et al., eds. GeneReviews ${ }^{\circledast}$. University of Washington; 1993. ncbi.nlm.nih.gov/books/ NBK1256/. (accessed September 6, 2020).

27. David G, Dürr A, Stevanin G, et al. Molecular and clinical correlations in autosomal dominant cerebellar ataxia with progressive macular dystrophy (SCA7). Hum Mol Genet. 1998;7(2):165-170.

28. Pulst SM. The complex structure of ATXN2 genetic variation. Neurol Genet. 2018; 4(6):e299.

29. Niu C, Prakash TP, Kim A, et al. Antisense oligonucleotides targeting mutant Ataxin-7 restore visual function in a mouse model of spinocerebellar ataxia type 7. Sci Transl Med. 2018;10(465):eaap8677.

30. Martin JJ. Spinocerebellar ataxia type 7. Handb Clin Neurol. 2012;103:475-491. 


\section{Neurology}

\section{Clinical Reasoning: A 28-Year-Old Woman With Vision Loss and an Unusual Gait}

Jenny C. Dohlman, Bart K. Chwalisz and Christopher D. Stephen

Neurology 2021;97;e1860-e1865 Published Online before print June 29, 2021

DOI 10.1212/WNL.000000000012446

This information is current as of June 29, 2021

\section{Updated Information \&} Services

References

Subspecialty Collections

Permissions \& Licensing

Reprints including high resolution figures, can be found at: http://n.neurology.org/content/97/18/e1860.full

This article cites 28 articles, 4 of which you can access for free at: http://n.neurology.org/content/97/18/e1860.full\#ref-list-1

This article, along with others on similar topics, appears in the following collection(s):

All Clinical Neurology

http://n.neurology.org/cgi/collection/all_clinical_neurology

All Movement Disorders

http://n.neurology.org/cgi/collection/all_movement_disorders

All Neuro-ophthalmology

http://n.neurology.org/cgi/collection/all_neuroophthalmology

Ocular motility

http://n.neurology.org/cgi/collection/ocular_motility

\section{Retina}

http://n.neurology.org/cgi/collection/retina

Information about reproducing this article in parts (figures,tables) or in its entirety can be found online at:

http://www.neurology.org/about/about_the_journal\#permissions

Information about ordering reprints can be found online:

http://n.neurology.org/subscribers/advertise

Neurology ${ }^{\circledR}$ is the official journal of the American Academy of Neurology. Published continuously since 1951, it is now a weekly with 48 issues per year. Copyright (C) 2021 American Academy of Neurology. All rights reserved. Print ISSN: 0028-3878. Online ISSN: 1526-632X.

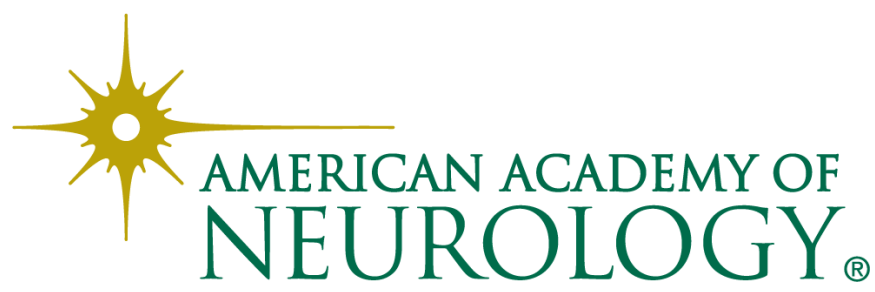

